\title{
Predicting Esophagitis After Chemoradiation Therapy for Non-Small Cell Lung Cancer: An Individual Patient Data Meta-Analysis
}

Citation for published version (APA):

Palma, D. A., Senan, S., Oberije, C., Belderbos, J., de Dios, N. R., Bradley, J. D., Barriger, R. B., MorenoJimenez, M., Kim, T. H., Ramella, S., Everitt, S., Rengan, R., Marks, L. B., De Ruyck, K., Warner, A., \& Rodrigues, G. (2013). Predicting Esophagitis After Chemoradiation Therapy for Non-Small Cell Lung Cancer: An Individual Patient Data Meta-Analysis. International Journal of Radiation Oncology Biology Physics, 87(4), 690-696. https://doi.org/10.1016/j.ijrobp.2013.07.029

Document status and date:

Published: 15/11/2013

DOI:

10.1016/j.ijrobp.2013.07.029

Document Version:

Publisher's PDF, also known as Version of record

\section{Document license:}

Taverne

Please check the document version of this publication:

- A submitted manuscript is the version of the article upon submission and before peer-review. There can be important differences between the submitted version and the official published version of record.

People interested in the research are advised to contact the author for the final version of the publication, or visit the DOI to the publisher's website.

- The final author version and the galley proof are versions of the publication after peer review.

- The final published version features the final layout of the paper including the volume, issue and page numbers.

Link to publication

\footnotetext{
General rights rights.

- You may freely distribute the URL identifying the publication in the public portal. please follow below link for the End User Agreement:

www.umlib.nl/taverne-license

Take down policy

If you believe that this document breaches copyright please contact us at:

repository@maastrichtuniversity.nl

providing details and we will investigate your claim.
}

Copyright and moral rights for the publications made accessible in the public portal are retained by the authors and/or other copyright owners and it is a condition of accessing publications that users recognise and abide by the legal requirements associated with these

- Users may download and print one copy of any publication from the public portal for the purpose of private study or research.

- You may not further distribute the material or use it for any profit-making activity or commercial gain

If the publication is distributed under the terms of Article 25fa of the Dutch Copyright Act, indicated by the "Taverne" license above, 


\title{
Predicting Esophagitis After Chemoradiation Therapy for Non-Small Cell Lung Cancer: An Individual Patient Data Meta-Analysis
}

\author{
David A. Palma, MD, MSc, PhD, * Suresh Senan, MRCP, FRCR, PhD, \\ Cary Oberije, MSc, PhD, Jose Belderbos, MD, PhD, \\ Núria Rodríguez de Dios, MD PhD, Jeffrey D. Bradley, MD, R. Bryan Barriger, MD,** \\ Marta Moreno-Jiménez, MD, PhD, ${ }^{\dagger \dagger}$ Tae Hyun Kim, MD, ${ }^{\ddagger \dagger}$ Sara Ramella, MD, \\ Sarah Everitt, PhD, \|\| Ramesh Rengan, MD, PhD, , Lawrence B. Marks, MD, *** \\ Kim De Ruyck, PhD, ${ }^{\dagger \dagger}$ Andrew Warner, MSc, ${ }^{*}$ and George Rodrigues, MD, MSc ${ }^{*}+\dagger \dagger$
}

*Department of Radiation Oncology, London Regional Cancer Program, London, Ontario, Canada, ${ }^{\dagger}$ Department of Radiation Oncology, VU University Medical Center, Amsterdam, The Netherlands, ${ }^{\ddagger}$ Department of Radiation Oncology (MAASTRO Clinic), GROW - School for Oncology and Developmental Biology, Maastricht University Medical Centre, Maastricht, The Netherlands, ${ }^{\S}$ Department of Radiation Oncology, The Netherlands Cancer Institute - Antoni van Leeuwenhoek Hospital, Amsterdam, The Netherlands, Department of Radiation Oncology, Parc de Salut Mar, Barcelona, Universidad Pompeu Fabra, Barcelona, Spain, "Department of Radiation Oncology, Washington University School of Medicine, St. Louis, Missouri, USA, **Department of Radiation Oncology, Indiana University School of Medicine, Indianapolis, Indiana, USA, ${ }^{\dagger \dagger}$ Department of Oncology, Radiation Oncology Division, Clínica Universidad de Navarra, University of Navarra, Pamplona, Spain, ${ }^{\ddagger \ddagger}$ Center for Proton Therapy, Research Institute and Hospital, National Cancer Center, Goyang, Gyeonggi, Korea, $\$ \S$ Division of Radiation Oncology, Campus Bio-Medico University, Rome, Italy, \|\| Radiation Therapy Services, Peter MacCallum Cancer Centre, Melbourne, Australia and Department of Medical Imaging and Radiation Sciences, Faculty of Medicine, Nursing \& Health Sciences, Monash University, Australia, ${ }^{\top \pi}$ Department of Radiation Oncology, University of Pennsylvania, Philadelphia, Pennsylvania, USA, ***Department of Radiation Oncology, University of North Carolina, Chapel Hill, North Carolina, USA, ${ }^{\dagger \dagger}$ Department of Basic Medical Sciences, Ghent University, Ghent, Belgium, and ${ }^{\ddagger \pm D}$ Department of Epidemiology and Biostatistics, University of Western Ontario, London, Ontario, Canada

Reprint requests to: David A. Palma, MD, MSc, PhD, Department of Radiation Oncology, London Regional Cancer Program, 790 Commissioners Rd E, London, Ontario, Canada, N6A4L6. Tel: (+1) 519-6858500; E-mail: david.palma@uwo.ca

Accepted for oral presentations at the Canadian Association of Radiation Oncologists' Annual Meeting 2013 and the 55th Annual Meeting of the American Society for Radiation Oncology (ASTRO), Atlanta, GA, September 22-25, 2013.

Supported by a clinician-scientist grant from the Ontario Institute for Cancer Research (to D.A.P.), and by National Institutes of Health Grant CA69579 (to L.B.M.)

Conflict of interest: Dr Senan has received research funding from Sanofi-Aventis and is a member of the trial management group (not reimbursed) for the phase 3 PROCLAIM study evaluating concurrent chemoradiation therapy schemes for stage III lung cancer, which is sponsored by Eli Lilly. Dr Barriger holds a leadership position with D3 Oncology Solutions, is a member of the Via Oncology Pathways Physician Advisory Committee, and is the Radiation Oncology Esophageal and Lung (Small Cell and Non-Small Cell) Committee Co-Chair. The authors report no other conflict of interest.

Acknowledgments - The authors thank Gabriel Bolt for assistance with literature review, and Drs Achilles Fakiris, Joke Bakker, Daniel Mullen, Ellen van Reij, Michael Lawrence, Eric Xanthopoulos, Shiva Das, Mary Duffy, Philippe Lambin, and David Ball for assistance with provision of data. 


\section{Summary}

This meta-analysis examined predictors of radiation esophagitis (RE) for patients receiving concurrent chemoradiation therapy for nonsmall cell lung cancer. Clinically significant $R E$ is common, but life-threatening complications occur in $<1 \%$ of patients. The esophageal volume receiving $\geq 60 \mathrm{~Gy}$ (V60) is the best predictor of $\mathrm{RE}$, and additional variables did not improve predictive ability. A V60 $<0.07 \%$ is associated with a low risk of $\mathrm{RE}$, whereas a V60 $\geq 17 \%$ confers the highest risk.
Purpose: Concurrent chemoradiation therapy (CCRT) improves survival compared with sequential treatment for locally advanced non-small cell lung cancer, but it increases toxicity, particularly radiation esophagitis (RE). Validated predictors of RE for clinical use are lacking. We performed an individual-patient-data meta-analysis to determine factors predictive of clinically significant RE.

Methods and Materials: After a systematic review of the literature, data were obtained on 1082 patients who underwent CCRT, including patients from Europe, North America, Asia, and Australia. Patients were randomly divided into training and validation sets $(2 / 3$ vs $1 / 3$ of patients). Factors predictive of $\mathrm{RE}$ (grade $\geq 2$ and grade $\geq 3$ ) were assessed using logistic modeling, with the concordance statistic (c statistic) used to evaluate the performance of each model.

Results: The median radiation therapy dose delivered was $65 \mathrm{~Gy}$, and the median follow-up time was 2.1 years. Most patients $(91 \%)$ received platinum-containing CCRT regimens. The development of RE was common, scored as grade 2 in 348 patients (32.2\%), grade 3 in 185 $(17.1 \%)$, and grade 4 in $10(0.9 \%)$. There were no RE-related deaths. On univariable analysis using the training set, several baseline factors were statistically predictive of $\operatorname{RE}(P<.05)$, but only dosimetric factors had good discrimination scores $(c>.60)$. On multivariable analysis, the esophageal volume receiving $\geq 60$ Gy (V60) alone emerged as the best predictor of grade $\geq 2$ and grade $\geq 3 \mathrm{RE}$, with good calibration and discrimination. Recursive partitioning identified 3 risk groups: low (V60<0.07\%), intermediate (V60 $0.07 \%$ to $16.99 \%$ ), and high $(\mathrm{V} 60 \geq 17 \%$ ). With use of the validation set, the predictive model performed inferiorly for the grade $\geq 2$ endpoint $(\mathrm{c}=.58)$ but performed well for the grade $\geq 3$ endpoint $(\mathrm{c}=.66)$.

Conclusions: Clinically significant RE is common, but life-threatening complications occur in $<1 \%$ of patients. Although several factors are statistically predictive of RE, the V60 alone provides the best predictive ability. Efforts to reduce the V60 should be prioritized, with further research needed to identify and validate new predictive factors. (C) 2013 Elsevier Inc.

\section{Introduction}

For patients with locally advanced non-small cell lung cancer (NSCLC), the addition of concurrent chemotherapy to radiation therapy provides the best chance of cure, achieving an absolute improvement in survival of $10 \%$ at 2 years in comparison with sequential chemotherapy and radiation (1). However, this improvement in survival comes at a cost: patients receiving concurrent chemoradiation therapy (CCRT) have an approximately 5-fold increase in the risk of acute radiation esophagitis (RE) compared with patients receiving sequential treatment, and in 1 randomized trial, $21 \%$ of patients on the CCRT arm had treatment discontinued because of severe RE (1). Symptoms of acute RE include odynophagia, dysphagia, and retrosternal pain, in some cases resulting in weight loss and requiring analgesics, intravenous fluids, hyperalimentation, the insertion of a percutaneous gastrostostomy tube, or some combination of these $(2,3)$.

The ability to accurately predict RE might facilitate strategies to mitigate risk and thus improve the therapeutic ratio. To that end, numerous studies have attempted to assess predictors of RE, examining patient and tumor characteristics, dosimetric factors, and the use of chemotherapy (2). However, such studies have not yet resulted in the widespread adoption of any prediction model, partly because of the heterogeneity of reported results across studies, the lack of external validation, and the inclusion of patients treated with older approaches (eg, sequential chemotherapy and radiation therapy) that may not be applicable to modern practice. One of the largest previous studies developed a practical prediction model (www.predictcancer.org) that was validated on 3 separate cohorts but included patients with small cell lung cancer and NSCLC, many of whom did not receive concurrent chemotherapy (4).
Recent guidelines for assessing normal tissue toxicity risk recommended the pooling of individual patient data to undertake meta-analyses in an effort to overcome some of the limitations of previous research (5). As a result, the collaborative project named Systematic analysis of toxicity after radical irradiation: pneumonitis and esophagitis (STRIPE) was launched to determine predictors of radiation pneumonitis and esophagitis in patients receiving CCRT. The first substudy examining predictors of radiation pneumonitis was recently reported (6). The goal of this component of the STRIPE project was to create and validate a predictive model for RE in a population of patients with locally advanced NSCLC receiving curative-intent, modern CCRT.

\section{Methods and Materials}

A systematic review was conducted using MEDLINE to identify articles published between 1993 and January 2011 reporting on dosimetric predictors of pneumonitis and RE. The full search strategy, including electronic searches and hand searches for data published in abstract form or unpublished, has been reported previously (6). Authors were contacted and invited to submit datasets (prospective or retrospective) with individual patient data. Institutional Research Ethics Board approval was obtained.

Individual patients were included in the analysis if they were treated for NSCLC with curative-intent CCRT, either 3-dimensional conformal radiation therapy (3D-CRT) or intensity modulated radiation therapy (IMRT). Exclusion criteria included stage IV disease, palliative-intent treatment, use of 2-dimensional radiation therapy planning, small cell histology, surgical resection, lack of esophagitis grade, and patients with no esophagitis dose metrics available. Induction or adjuvant CCRT was permitted. Patients who discontinued treatment because of toxicity (and 
therefore did not receive the intended dose) were included. All centers reported contouring the esophagus from cricoid to gastroesophageal junction as standard practice, and 1 center routinely used contrast medium to assist in esophageal delineation.

The 2 endpoints of this study were: (1) severe acute RE, defined as grade 3 or higher according to the Common Terminology Criteria for Adverse Events version 3 or 4, or grade 3 or higher on the Radiation Therapy and Oncology Group (RTOG) scale; and (2) moderate acute RE, defined as grade 2 or higher on the same scales, which has been previously defined as a clinically significant measure across multiple scoring scales (3). Patients recorded as having RE during or after RT were recorded as having an event.

\section{Statistical analysis}

A random number generator was used to separate patients into a training set $(n=722,2 / 3$ of 1082$)$ and a validation set $(n=360$, $1 / 3$ of 1082) without stratification. Descriptive statistics were generated for baseline patient, tumor, and treatment characteristics. Using the training set, univariable logistic regression analysis was performed for each of the eligible available factors to identify significant predictors of esophagitis grade $\geq 2$ and grade $\geq 3$. Due to the fact that patients with missing data fields are excluded from any regression analysis using those fields, it was required that any predictor was available on at least 200 patients to be assessed as a predictor. Imputation was not used because the data were missing in a nonrandom fashion. By use of univariable analysis, $P$ values and concordance statistics (c statistics) were used to quantify degree of association between each of the factors and esophagitis endpoints. The $\mathrm{c}$ statistic indicates the discrimination of the model (ie, the ability to distinguish low-risk from high-risk study participants), and it ranges from .5 to 1 , with .5 indicating a useless test (no better than chance) and 1 indicating a perfect test (7). For any 2 randomly selected patients of whom 1 has the outcome of interest (RE) and 1 does not, the c statistic denotes how often the model identifies the high-risk patient correctly.

Multivariable logistic regression models were then generated by the use of forward-stepwise selection procedures, with factors significant on univariable analysis eligible for inclusion in the multivariable model. Factors remained included in the model if they met 3 criteria: the factor was a statistically significant predictor, the factor increased the discrimination of the model (denoted by a higher $\mathrm{c}$ statistic), and the model was well calibrated, indicating that the predicted risk for an individual patient is similar to the actual risk, as judged by the Hosmer-Lemeshow test (7).

Recursive partitioning analysis (RPA) was performed incorporating significant predictors of esophagitis identified from multivariable logistic regression as described previously (6) and was used to create risk groups. RPA cutoffs were rounded to increase clinical utility.

Once the analysis was complete on the training set, the performance of the model and the RPA were evaluated by use of the validation set. Survival estimates were calculated with the Kaplan-Meier method, and the median follow-up time was calculated with the reverse Kaplan-Meier method. Statistical analysis was performed with SAS, version 9.2 (Cary, NC), and R, version 2.15.2 (Vienna, Austria, for recursive partitioning analysis only), with the use of 2-sided statistical testing at the .05 significance level. For the Hosmer-Lemeshow test of calibration, the null hypothesis is that a model is well calibrated, such that $P<.05$ indicates poor calibration.

\section{Results}

Data were available on 1082 patients from 15 different sources, 12 previously reported in whole or in part -11 articles $(4,8-17)$ and 1 abstract (18) - representing patients from North America, Europe, Asia, and Australia (Table 1). Baseline clinical characteristics are shown in Table 2. The median follow-up time was 26 months, and the median overall survival was 19 months. The median total dose delivered was 65 Gy (range, 14-81.6 Gy), and most patients received $\leq 2$ Gy per fraction (85.2\%). Numerous chemotherapy regimens were used, with $91 \%$ of patients receiving a platinum-containing regimen.

The development of RE was common, scored as grade 2 in 348 patients $(32.2 \%)$, grade 3 in 185 patients $(17.1 \%)$, and grade 4 in 10 patients $(0.9 \%)$. There were no esophagitis-related deaths.

Table 1 Sources of individual patient data

\begin{tabular}{lr}
\hline \multicolumn{1}{c}{ Institution } & No. of patients \\
\hline MAASTRO Clinic, Maastricht, The Netherlands & 228 \\
The Netherlands Cancer Institute - Antoni van Leeuwenhoek Hospital, & 136 \\
Amsterdam, Netherlands & 100 \\
Universidad Pompeu Fabra, Barcelona, Spain & 80 \\
Washington University School of Medicine, St. Louis, USA & 73 \\
Indiana University School of Medicine, Indianapolis, USA & 71 \\
Pulmonart Multicenter Study & 67 \\
University of Navarra, Pamplona, Spain & 65 \\
National Cancer Center, Goyang, Korea & 64 \\
London Regional Cancer Program & 63 \\
Campus Bio-Medico University, Rome, Italy & 58 \\
VU University Medical Center, Amsterdam, Netherlands & 42 \\
Peter MacCallum Cancer Centre, Melbourne, Australia & 18 \\
University of Pennsylvania, Philadelphia, USA & 11 \\
Duke University, Durham, USA & 6 \\
Ghent University Hospital, Ghent, Belgium & 1082 \\
Total &
\end{tabular}


Table 2 Baseline clinical characteristics

\begin{tabular}{|c|c|c|}
\hline Characteristic & $\mathrm{N}$ with data available at individual patient level & Median (range) or $\mathrm{n}(\%)$ \\
\hline Age & 1081 & $63.00(24.53,85.00)$ \\
\hline Sex & 1082 & \\
\hline Male & & $750(69.3)$ \\
\hline Female & & $332(30.7)$ \\
\hline Histology & 865 & \\
\hline Adenocarcinoma & & $234(27.1)$ \\
\hline Squamous & & $288(33.3)$ \\
\hline Large cell & & $153(17.7)$ \\
\hline Other/NOS /undifferentiated & & $190(22.0)$ \\
\hline Stage* & 954 & \\
\hline I & & $8(0.8)$ \\
\hline II & & $38(4.0)$ \\
\hline III & & $908(95.2)$ \\
\hline T stage & 955 & \\
\hline T0 & & $5(0.5)$ \\
\hline $\mathrm{T} 1$ & & $97(10.2)$ \\
\hline $\mathrm{T} 2$ & & $302(31.6)$ \\
\hline $\mathrm{T} 3$ & & $208(21.8)$ \\
\hline $\mathrm{T} 4$ & & $316(33.1)$ \\
\hline TX & & $27(2.8)$ \\
\hline $\mathrm{N}$ stage & 955 & \\
\hline No & & $121(12.7)$ \\
\hline N1 & & $57(6.0)$ \\
\hline $\mathrm{N} 2$ & & $522(54.7)$ \\
\hline N3 & & $244(25.6)$ \\
\hline NX & & $11(1.2)$ \\
\hline Smoking history & 538 & \\
\hline Yes, current or former & & $504(93.7)$ \\
\hline Never & & $34(6.3)$ \\
\hline Performance status & 709 & \\
\hline Good (ECOG $0-1$ or KPS $\geq 70$ ) & & $655(92.4)$ \\
\hline Poor $(\mathrm{ECOG} \geq 2$ or $\mathrm{KPS} \leq 70)$ & & $54(7.6)$ \\
\hline Neoadjuvant chemotherapy & 222 & $139(62.6)$ \\
\hline Type of concurrent chemotherapy & 771 & \\
\hline Platinum-based + etoposide & & $208(27.0)$ \\
\hline Platinum-based + taxane & & $210(27.2)$ \\
\hline Other platinum-based & & $287(37.2)$ \\
\hline Other/not specified & & $66(8.6)$ \\
\hline Max dose to esophagus (Gy) & 933 & $65.40(0.40,81.90)$ \\
\hline Mean dose to esophagus (Gy) & 561 & $32.60(1.90,68.70)$ \\
\hline Esophagus V5 (\%) & 269 & $64.28(20.64,100.00)$ \\
\hline Esophagus V10 (\%) & 369 & $58.39(5.00,100.00)$ \\
\hline Esophagus V15 (\%) & 206 & $59.42(11.08,99.60)$ \\
\hline Esophagus V20 (\%) & 411 & $48.63(0.00,100.00)$ \\
\hline Esophagus V25 (\%) & 248 & $49.54(0.00,97.99)$ \\
\hline Esophagus V30 (\%) & 429 & $44.06(0.00,100.00)$ \\
\hline Esophagus V35 (\%) & 348 & $45.19(0.00,100.00)$ \\
\hline Esophagus V40 (\%) & 411 & $39.00(0.00,100.00)$ \\
\hline Esophagus V45 (\%) & 478 & $38.14(0.00,100.00)$ \\
\hline Esophagus V50 (\%) & 502 & $29.21(0.00,98.70)$ \\
\hline Esophagus V55 (\%) & 489 & $22.26(0.00,95.00)$ \\
\hline Esophagus V60 (\%) & 486 & $11.04(0.00,93.64)$ \\
\hline
\end{tabular}

Abbreviations: $\mathrm{ECOG}=$ Eastern Cooperative Oncology Group; NOS = not otherwise specified.

* All staging data refer to AJCC, sixth edition. 
The results from the univariable analysis on the training dataset $(n=722)$ are shown in Table 3. Univariable analysis identified numerous baseline variables that were significantly associated with each RE endpoint (grade $\geq 2$ and grade $\geq 3$ ), but most performed poorly as predictors (c statistic .5-.6). Only dosimetric variables were significant predictors of RE with $\mathrm{c}>.6$. For both endpoints, the best individual predictor was V60 (For grade $\geq 2$ : OR 1.34 per $10 \%$ increase, $\mathrm{c}=.671, P<.001$; for grade $\geq 3$ : OR 1.33 per $10 \%$ increase, $\mathrm{c}=.694, P<.001$ ); with other high-dose parameters V50 to V70 among the best predictors.

On multivariable analysis using the training dataset, for both endpoints, the V60 alone formed the best predictive model. For the grade $\geq 2$ RE multivariable model, "number of fractions" was a significant predictor (OR 0.59 per 5 -fraction increase, $P<.001$ ) along with V60, but the $\mathrm{c}$ statistic improved only slightly (from .671 with V60 alone to .686), and the model failed the test of calibration (Hosmer-Lemeshow $P=.02$ ). As such, the best model was deemed to be V60 alone. For grade $\geq 3$ RE, V60 was the only significant predictor in the final multivariable model, with no other variables reaching statistical significance.

Recursive partition analysis divided the training dataset into 3 risk groups based on the V60 values (Fig. 1). A low-risk subgroup was identified with a very low V60 of $<0.07 \%$, an intermediaterisk subgroup with a V60 of $0.07 \%$ to $16.99 \%$, and a high-risk subgroup with a V60 of $\geq 17 \%$. Patients were well distributed between groups: in the whole dataset, of the 486 patients with V60 data available, 147 (30\%) were in the low-risk group, $125(26 \%)$ were in the intermediate-risk group, and 214 (44\%) were in the high-risk group. These numbers were similar in the training versus the validation sets: $29 \%$ versus $32 \%$ in the low-risk group, $27 \%$ versus $23 \%$ in the intermediate-risk group, and $44 \%$ versus $45 \%$ in the high-risk group.

The findings from the training set were then assessed in the validation set $(n=360)$. For grade $\geq 2 R E$, the predictive model (V60 alone) did not perform as well as in the training set, with a final c statistic of .583 , whereas for grade $\geq 3 \mathrm{RE}$, the model

Table 3 Univariable logistic regression models examining relationship between individual predictors of esophagitis grade $\geq 2$ and grade $\geq 3$ in the training set $(n=722)$

\begin{tabular}{|c|c|c|c|c|c|c|}
\hline \multirow[b]{2}{*}{ Independent variable } & \multicolumn{3}{|c|}{ Grade $\geq 2$ esophagitis } & \multicolumn{3}{|c|}{ Grade $\geq 3$ esophagitis } \\
\hline & Odds ratio $(95 \% \mathrm{CI})$ & $P$ value & c statistic & Odds ratio $(95 \% \mathrm{CI})$ & $P$ value & c statistic \\
\hline Age (per 10-year increase) & $0.98(0.84,1.14)$ & .774 & 0.507 & $0.93(0.76,1.12)$ & .433 & 0.521 \\
\hline Male sex (ref: female) & $0.84(0.61,1.15)$ & .270 & 0.519 & $1.28(0.84,1.94)$ & .255 & 0.525 \\
\hline Stage (stage III vs lower)* & $2.31(1.09,4.89)$ & .029 & 0.520 & $3.55(0.84,15.02)$ & .085 & 0.522 \\
\hline $\mathrm{T}$ stage $(\mathrm{T} 4 \text { vs } \mathrm{T} 1)^{*}$ & $0.95(0.54,1.66)$ & .854 & 0.549 & $1.01(0.46,2.26)$ & .113 & 0.565 \\
\hline $\mathrm{N}$ stage (N3 vs. $\mathrm{N} 0)^{*}$ & $2.17(1.25,3.75)$ & .015 & 0.561 & $7.50(2.24,25.16)$ & .011 & 0.593 \\
\hline Histology* & & .298 & 0.542 & & .130 & 0.561 \\
\hline Current or former smoker (ref: never) & $0.58(0.25,1.36)$ & .210 & 0.517 & $0.94(0.34,2.60)$ & .907 & 0.502 \\
\hline Poor performance status (ref: good) & $2.34(1.11,4.92)$ & .026 & 0.528 & $0.80(0.34,1.88)$ & .614 & 0.508 \\
\hline Type of concurrent chemotherapy* & & .005 & 0.565 & & .283 & 0.549 \\
\hline $\begin{array}{l}\text { Total radiation dose (Gy) (per 5-Gy } \\
\text { increase) }\end{array}$ & $0.98(0.86,1.11)$ & .758 & 0.507 & $0.91(0.78,1.06)$ & .213 & 0.539 \\
\hline $\begin{array}{l}\text { Total number of fractions (per 5-unit } \\
\text { increase) }\end{array}$ & $0.88(0.81,0.97)$ & .008 & 0.547 & $0.83(0.73,0.95)$ & .006 & 0.580 \\
\hline Fractionation schedule & & .002 & 0.565 & & .423 & 0.532 \\
\hline Dose per fraction (per 1-Gy increase) & $1.72(1.18,2.51)$ & .005 & 0.542 & $1.77(1.13,2.77)$ & .013 & 0.577 \\
\hline $\begin{array}{l}\text { Max dose to esophagus (Gy) (per 5-Gy } \\
\text { increase) }\end{array}$ & $1.18(1.08,1.30)$ & $<.001$ & 0.576 & $1.10(0.97,1.23)$ & .131 & 0.535 \\
\hline $\begin{array}{l}\text { Mean dose to esophagus (Gy) (per 5-Gy } \\
\text { increase) }\end{array}$ & $1.09(1.00,1.20)$ & .062 & 0.555 & $1.16(1.02,1.31)$ & .020 & 0.608 \\
\hline Esophagus V5 (\%) (per $10 \%$ increase) & $1.34(1.09,1.63)$ & .005 & 0.618 & $1.35(1.05,1.74)$ & .018 & 0.630 \\
\hline Esophagus V10 (\%) (per 10\% increase) & $1.23(1.06,1.44)$ & .007 & 0.597 & $1.30(1.06,1.60)$ & .013 & 0.638 \\
\hline Esophagus V15 (\%) (per 10\% increase) & $1.29(1.02,1.62)$ & .031 & 0.609 & $1.19(0.93,1.52)$ & .160 & 0.579 \\
\hline Esophagus V20 (\%) (per 10\% increase) & $1.15(1.04,1.28)$ & .007 & 0.605 & $1.14(0.99,1.31)$ & .070 & 0.606 \\
\hline Esophagus V25 (\%) (per 10\% increase) & $1.21(1.07,1.38)$ & .003 & 0.644 & $1.12(0.97,1.30)$ & .114 & 0.589 \\
\hline Esophagus V30 (\%) (per 10\% increase) & $1.22(1.10,1.35)$ & $<.001$ & 0.638 & $1.17(1.02,1.34)$ & .028 & 0.613 \\
\hline Esophagus V35 (\%) (per 10\% increase) & $1.16(1.03,1.29)$ & .011 & 0.604 & $1.12(0.97,1.28)$ & .123 & 0.583 \\
\hline Esophagus V40 (\%) (per 10\% increase) & $1.21(1.09,1.34)$ & $<.001$ & 0.636 & $1.20(1.05,1.38)$ & .010 & 0.628 \\
\hline Esophagus V45 (\%) (per 10\% increase) & $1.12(1.02,1.23)$ & .021 & 0.579 & $1.15(1.01,1.31)$ & .033 & 0.598 \\
\hline Esophagus V50 (\%) (per 10\% increase) & $1.28(1.15,1.42)$ & $<.001$ & 0.662 & $1.25(1.09,1.44)$ & .001 & 0.647 \\
\hline Esophagus V55 (\%) (per 10\% increase) & $1.22(1.09,1.36)$ & $<.001$ & 0.634 & $1.25(1.09,1.43)$ & .002 & 0.655 \\
\hline Esophagus V60 (\%) (per 10\% increase) & $1.34(1.19,1.52)$ & $<.001$ & 0.671 & $1.33(1.15,1.54)$ & $<.001$ & 0.694 \\
\hline Esophagus V65 (\%) (per 10\% increase) & $1.32(1.06,1.63)$ & .012 & 0.646 & $1.14(0.93,1.40)$ & .198 & 0.581 \\
\hline Esophagus V70 (\%) (per 10\% increase) & $1.72(1.19,2.48)$ & .004 & 0.667 & $1.52(1.08,2.15)$ & .017 & 0.689 \\
\hline
\end{tabular}

Abbreviations: $\mathrm{CI}=$ confidence interval; $\mathrm{Vx}=$ volume of esophagus receiving $\geq \times$ Gy of radiation therapy.

* Because of space limitations, data for specific subgroups of categorical variables with $>2$ subgroups (nominal or ordinal) are omitted; for ordinal variables data comparing the first and last categories are presented, whereas for nominal variables the $P$ value for the whole group is provided. 
(V60 alone) had similar performance characteristics as in the training set $(\mathrm{c}=.655)$. Application of the risk categories formed by the RPA to the validation set was consistent with results from the training data set (Fig. 1).

\section{Discussion}

Radiation esophagitis is a common adverse event in patients receiving CCRT and can have a deleterious impact on quality of life and treatment compliance $(2,3)$. This study, which to our knowledge is the largest such study reported to date on patients receiving CCRT, suggests that high-dose metrics are the most important predictors of RE. The V60 emerged as the best predictor for both moderate and severe RE. Patients with a very low V60 $<1 \%$ have a low risk of $\mathrm{RE}(<5 \%$ risk of grade $\geq 3$ toxicity), whereas a V60 above $17 \%$ confers a high risk of RE. Other highdose metrics, such as the V50, also serve as good predictors of RE. Despite these risks of symptomatic RE, the chance of lifethreatening toxicity is low ( $<1 \%$ grade $4 \mathrm{RE}$ ), and no RErelated deaths were reported. In the context of the challenges achieving local control for NSCLC, this very low risk of lifethreatening toxicity suggests that although the dose to the esophagus should be as low as reasonably achievable, delivering adequate dose to tumor should be prioritized, as long as treatment interruptions in patients who experience RE can be avoided.

This study is also unique in that it identifies predictors of toxicity based on their discrimination and calibration, not merely based on $P$ values. Although several previous articles have reported significant predictors of RE based on statistical significance alone, without information regarding the performance of each predictor, the clinical utility of such models is unknown. Indeed, several baseline factors examined herein were significant predictors of RE (Table 3) yet did not perform much better than random chance in discriminating between patients (eg, the presence of stage III disease was a significant predictor, but the $\mathrm{c}$ statistic of 0.52 indicates that it is only marginally better than a coin toss).

The findings of this study are consistent with previously reported data examining predictors of RE, including studies examining patients treated with radiation therapy alone. Although some studies have suggested that the low-dose metrics are associated with toxicity, most studies implicate the high-dose metrics (eg, cumulative dose $>50 \mathrm{~Gy}$ ) as being most strongly associated with
RE $(2,3)$. These findings are consistent with the classification of the esophagus as a serial organ at risk, in that a large dose to a small volume can result in significant toxicity. However, it is likely that other key variables play an important role in the development of RE. A previous study from the Netherlands, which contributed data to the meta-analysis herein, identified age, sex, performance status, mean and maximum esophageal dose, and overall treatment time as predictors of RE. This model performed very well on external validation, with c statistics of .94 for a separate Northern European dataset and .77 for a dataset from Washington University-much better than physicians' predictions, which were similar to chance, with $c=.53$ (4). Several more complex dose metrics have been considered (such as metrics based on surface area, esophageal circumference, or length of esophagus receiving a certain threshold dose), but their utility over more traditional dose-volume metrics is unclear. The use of concurrent chemotherapy (vs radiation therapy alone) has also been implicated in the development of RE (12). Given that all patients in this meta-analysis received concurrent chemotherapy, this could not be assessed directly, although the different chemotherapy agents did not seem to affect RE risk, as they appear to do with pneumonitis risk (6).

These findings take on additional importance in the context of recent developments in radiation therapy that may be helpful for reducing the risk of esophageal toxicity without compromising the dose delivered to tumor. The use of IMRT for patients with nodepositive disease, or with tumors close to the esophagus, can achieve significant esophageal sparing relative to 3D-CRT. In node-positive patients, 1 planning study achieved a decrease in esophageal V50 from $26 \%$ to $28 \%$ with 3D-CRT to $19 \%$ with the use of IMRT while maintaining equivalent tumor control probability (19). Elective nodal irradiation (ENI) has also been clearly associated with increased esophageal dose, resulting in a 2-fold increase in the esophageal V50 compared with plans treating only involved nodes (19). Current treatment planning recommendations suggest that ENI can be omitted in the treatment of NSCLC when positron emission tomography-computed tomography scans are used as a component of routine staging (20), although this remains somewhat controversial.

Meta-analyses are powerful tools for creating predictive models because of their statistical power and generalizability, but several limitations must be borne in mind. The models and risk groups created in this study, relying on V60 alone, are useful to guide clinical practice but require further improvement. Overfitting of

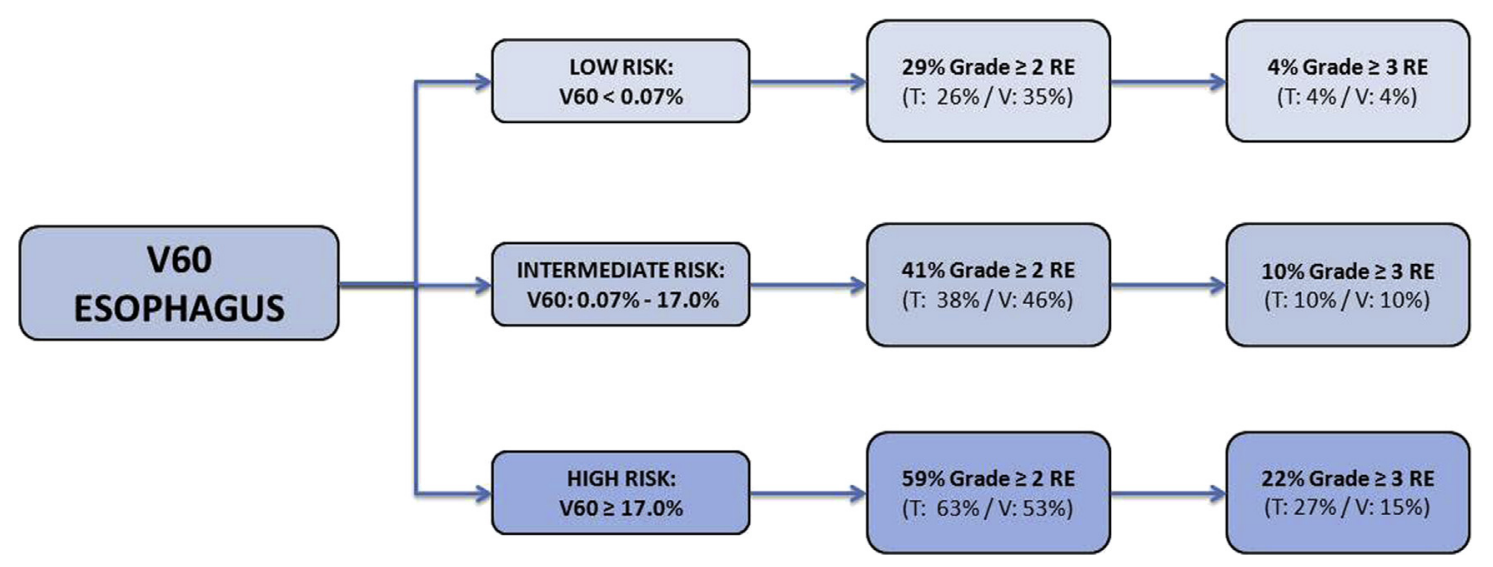

Fig. 1. Recursive partitioning analysis showing groups at low risk, intermediate risk, and high risk for radiation esophagitis (RE). $\mathrm{T}=$ training set; $\mathrm{V}=$ validation set; $\mathrm{V} 60=$ volume of esophagus receiving $\geq 60$ Gy of radiation therapy. 
training data is a common issue in prediction modeling, and this was evident herein. For the endpoint of moderate esophagitis (grade $\geq 2$ ), the model did not perform well in the validation set $(c<.6)$, suggesting that the generalizability of the model for the grade $\geq 2$ outcome may be limited. For the grade $\geq 3$ endpoint, although there was less overfitting based on the c statistics, the differences in absolute RE risk in the 3 risk groups was smaller: approximately $5 \%$. It is clear that the incorporation of novel predictors, such as genetic biomarkers, is required to create more accurate and robust models, ideally with c statistics $>.80$.

When data are pooled from several centers, information is not always widely available on all variables of interest such as neutropenia (4), genetic polymorphisms, craniocaudal tumor dimension, the presence of bulky lymphadenopathy, and specific radiation therapy planning approaches such as the use of elective nodal irradiation, and some datasets did not include data on all important variables herein. Specifically, many of the dosimetric variables were available on fewer than half of the patients, limiting the statistical power.

The utility of V60 as a predictive marker may vary on the basis of local image segmentation practices, in that smaller esophageal volumes tend to increase the V60. However, current guidelines suggest that the esophageal volume should extend from the cricoid to the gastroesophageal junction (3), and all centers reported following this practice, but this cannot be verified at the individual patient data level, and as such there may be some variability in contouring that affects the true V60 measurement. In addition, the nominal doses reported herein were not corrected for fractionation; however, this would not be expected to have a major impact because the majority of patients received 1.8 to 2 Gy per day; similarly, data on the use of inhomogeneity correction algorithms were not available in sufficient numbers to allow for inclusion of this factor in the modeling. Although the use of 3D-CRT versus IMRT and ENI were not available at the individual patient level, the effects of these planning approaches would be reflected in the dose-volume parameters evaluated herein (19). There can be uncertainty in ascertaining true RE at different centers, which can be mistaken for esophageal infection or worsening of gastroesophageal reflux (3). Ideally, some of these limitations should be addressed through the creation of a large, multicenter database prospectively collecting data on all variables of interest, or even a randomized trial addressing the value of reducing the V60. The ability to reduce the V60 must be considered in the context of other competing priorities, including the risk of pneumonitis, myelitis, and the tumor control probability, and such tradeoffs may depend on the individual patient circumstances.

In conclusion, although RE is a common toxicity of CCRT, lifethreatening RE is rare, and no RE-related deaths were reported in this large cohort of patients. High-dose metrics, specifically the V60, are the best predictors of RE. Modern planning techniques such as IMRT and avoidance of ENI may be useful in reducing the risk of RE while maintaining adequate dose to target volumes.

\section{References}

1. O'Rourke N, Roque IFM, Farre Bernado N, et al. Concurrent chemoradiotherapy in non-small cell lung cancer. Cochrane Database Syst Rev 2010;CD002140.

2. Rose J, Rodrigues G, Yaremko B, et al. Systematic review of dosevolume parameters in the prediction of esophagitis in thoracic radiotherapy. Radiother Oncol 2009;91:282-287.
3. Werner-Wasik M, Yorke E, Deasy J, et al. Radiation dose-volume effects in the esophagus. Int J Radiat Oncol Biol Phys 2010;76:S86-S93.

4. Dehing-Oberije C, De Ruysscher D, Petit S, et al. Development, external validation and clinical usefulness of a practical prediction model for radiation-induced dysphagia in lung cancer patients. Radiother Oncol 2010;97:455-461.

5. Jackson A, Marks LB, Bentzen SM, et al. The lessons of QUANTEC: Recommendations for reporting and gathering data on dose-volume dependencies of treatment outcome. Int J Radiat Oncol Biol Phys 2010;76:S155-S160.

6. Palma DA, Senan S, Tsujino K, et al. Predicting radiation pneumonitis after chemoradiation therapy for lung cancer: An international individual patient data meta-analysis. Int J Radiat Oncol Biol Phys 2013; 85:444-450.

7. LaValley MP. Logistic regression. Circulation 2008;117:2395-2399.

8. Phernambucq EC, Spoelstra FO, Verbakel WF, et al. Outcomes of concurrent chemoradiotherapy in patients with stage III non-smallcell lung cancer and significant comorbidity. Ann Oncol 2011;22: 132-138.

9. Senan S, Cardenal F, Vansteenkiste J, et al. A randomized phase II study comparing induction or consolidation chemotherapy with cisplatin-docetaxel, plus radical concurrent chemoradiotherapy with cisplatin-docetaxel, in patients with unresectable locally advanced non-small-cell lung cancer. Ann Oncol 2011;22:553-558.

10. Barriger RB, Fakiris AJ, Hanna N, et al. Dose-volume analysis of radiation pneumonitis in non-small-cell lung cancer patients treated with concurrent cisplatinum and etoposide with or without consolidation docetaxel. Int J Radiat Oncol Biol Phys 2010;78:1381-1386.

11. Fernandes AT, Shen J, Finlay J, et al. Elective nodal irradiation (ENI) vs. involved field radiotherapy (IFRT) for locally advanced non-small cell lung cancer (NSCLC): A comparative analysis of toxicities and clinical outcomes. Radiother Oncol 2010;95:178-184.

12. Huang EX, Bradley JD, El Naqa I, et al. Modeling the risk of radiation-induced acute esophagitis for combined Washington University and RTOG trial 93-11 lung cancer patients. Int J Radiat Oncol Biol Phys 2012;82:1674-1679.

13. De Ruyck K, Sabbe N, Oberije C, et al. Development of a multicomponent prediction model for acute esophagitis in lung cancer patients receiving chemoradiotherapy. Int J Radiat Oncol Biol Phys 2011;81: 537-544.

14. Rodriguez N, Algara M, Foro P, et al. Predictors of acute esophagitis in lung cancer patients treated with concurrent three-dimensional conformal radiotherapy and chemotherapy. Int $J$ Radiat Oncol Biol Phys 2009;73:810-817.

15. Song CH, Pyo H, Moon SH, et al. Treatment-related pneumonitis and acute esophagitis in non-small-cell lung cancer patients treated with chemotherapy and helical tomotherapy. Int J Radiat Oncol Biol Phys 2010;78:651-658.

16. Kim TH, Cho KH, Pyo HR, et al. Dose-volumetric parameters of acute esophageal toxicity in patients with lung cancer treated with threedimensional conformal radiotherapy. Int $J$ Radiat Oncol Biol Phys 2005;62:995-1002.

17. Kwint M, Uyterlinde W, Nijkamp J, et al. Acute esophagus toxicity in lung cancer patients after intensity modulated radiation therapy and concurrent chemotherapy. Int J Radiat Oncol Biol Phy 2012;84:e223e228.

18. Louie AV, Rodrigues G, Lee P, et al. Clinical and technical assessment of respiratory gated intensity modulated radiotherapy for locally advanced lung cancer. Int J Radiat Oncol Biol Phys 2011;81:S824.

19. Grills IS, Yan D, Martinez AA, et al. Potential for reduced toxicity and dose escalation in the treatment of inoperable non-small-cell lung cancer: A comparison of intensity-modulated radiation therapy (IMRT), 3D conformal radiation, and elective nodal irradiation. Int $J$ Radiat Oncol Biol Phys 2003;57:875-890.

20. De Ruysscher D, Faivre-Finn C, Nestle U, et al. European Organisation for Research and Treatment of Cancer recommendations for planning and delivery of high-dose, high-precision radiotherapy for lung cancer. J Clin Oncol 2010;28:5301-5310. 